\title{
Desobediencia Civil Indígena: El pueblo Nasa y el incidente del Cerro Berlín
}

\author{
Gilma Liliana Ballesteros Peluffo \\ Asesora gubernamental, docente e investigadora. \\ Universidad de Bogotá Jorge Tadeo Lozano \\ Email: gilmabp@hotmail.com
}

\begin{abstract}
Resumen: El artículo tiene el objetivo de revelar formas espontáneas de desobediencia civil, en la que los indígenas se manifiestan en contra de una postura institucional, como la guerra, a través de acciones noviolentas. Sus manifestaciones no solo señalan las injusticias que trae consigo el ejercicio de la violencia, sino que su postura invita a reflexionar sobre la actitud de los ciudadanos frente a la organización para la transformación positiva, la defensa de los derechos y el rechazo a la guerra.

Palabras clave: Noviolencia, Desobediencia Civil, Indígenas Nasa, Resistencia Civil, Conflicto Armado.
\end{abstract}

\section{Indigenous civil disobedience: the Nasa people and the Berlin mountain}

\begin{abstract}
The article aims to reveal spontaneous forms of civil disobedience, in which the Indians demonstrate against an institutional position, as is the war, through nonviolent actions. Its manifestations do not only point out the injustices brought up by the exercise of violence, but invites reflection on the attitude of citizens in regards the organization for positive transformation, the defense of
\end{abstract} rights and the rejection of war.

Key words: Nonviolence, civil disobedience, Indigenous Nasa , Civil Resistance Armed Conflict.

\section{Desobediência Civil Indígena: O povo Nasae o incidente do Morro Berlím}

Resumo:O artigo tem como objetivo revelar as formas espontâneas de desobediência civil, na qualos indígenas se manifestamem contra de uma postura institucional, como a guerra, através de ações não violentas. Suas manifestações não somente assinalamasinjustiças que traz consigo o exercício daviolência, mas que sua posição convida a refletir sobre aatitude doscidadãos frente à organização para atransformação positiva, a defensa dosdireitose a rejeição à guerra.

Palavras chaves: Não-violência,Desobediência Civil, Indígenas Nasa, Resistencia Civil, Conflito Armado. 
Los indígenas del Norte del Cauca se cansaron de la guerra. Durante el mes de julio del año 2012 toda Colombia se enteró por los medios de comunicación de su postura frente al conflicto: no tolerar ningún enfrentamiento armado en sus territorios. Esto significa, en la práctica, expulsar tanto a militares como a guerrilleros, valiéndose de la autoridad representada en el bastón de mando - una pequeña vara de madera con cintas de colores - en las manos de la guardia indígena, así como de una serie de acciones que incluyen marchas, concentraciones y diferentes tipos de presión social en los medios de comunicación. En palabras de Feliciano Valencia, líder del Concejo Regional del Cauca -CRIC—: "nos cansamos de la guerra aunque respetamos al Gobierno y a la Constitución (...) tenemos derecho a la paz" (Arias 2012).

La serie de enfrentamientos entre la guardia indígena y el ejército colombiano alcanzó su cenit el 17 de julio de 2012, cuando la primera se tomó el Cerro Berlín, posición estratégica sobre el municipio de Toribio, custodiada por el ejército colombiano. Los indígenas marcharon al Cerro, rodearon la base militar y se encontraron con los militares que se resistieron a marcharse. Lo que ocurrió luego fue materia de intenso debate por algunos días en todo el país: los indígenas, a empujones, sacaron a los soldados y suboficiales, quienes aferrados a su fusil tuvieron que dejar sus posiciones. Como lo narra un periodista de la Revista Semana:

Con el careo entre militares e indígenas se armó la de troya en el cerro. Primero, porque los indígenas le exigían a los soldados que se fueran del lugar, mientras que los militares respondían con timidez que de ese sitio los tenían que sacar cargados. Y así fue; por la fuerza varios indígenas cogieron de pies y manos a los militares para retirarlos, pero en algunos casos esa acción se mezcló con empujones y el llanto de uno de los soldados que impotente reclamaba respeto. "Debo reconocer que allí nos equivocamos”, dijo Feliciano Valencia, líder de la guardia indígena. El momento más tenso se vivió cuando la guardia rodeó al oficial que estaba a cargo de esa unidad militar; de inmediato sus hombres respondieron con disparos al aire para dispersar a los indígenas, pero la acción solo sirvió para causar más confusión. (Murcia 2012)

Las imágenes se repetían sin cesar en los televisores y redes sociales virtuales. Los militares, levantados de manos y pies, siendo arrastrados cerro abajo. Un suboficial llora de impotencia, mientras otros relatarán luego cómo los indígenas les gritaban arengas, les escupían y les insultaban. En la madrugada del día siguiente, el Presidente colombiano, Juan Manuel Santos envió el siguiente tuit, condenando lo sucedido: "No quiero ver un solo indígena en bases militares” (Sierra 2012). Luego declaró:

Gobierno respeta a las comunidades indígenas y su deseo por dialogar, pero que no (sic) permitirá ataques contra los soldados, son hechos inaceptables que constituyen conductas penales y deber ser investigadas por las autoridades y agregó que como presidente 
de todos los colombianos rechaza categóricamente dicha actitud y hace un vehemente llamado para que cesen las hostilidades. (ElPlaneta.co 2012)

El mismo 17 de julio, el ex presidente Álvaro Uribe, en un tono más beligerante, escribió el siguiente tuit: “Cómo se permite la masacre de nuestros soldados! Cómo se pretende seguridad si se permite humillar a nuestros soldados” (León 2012). Esta expresión se sumaba a una serie de críticas que el ex mandatario venía realizando al gobierno Santos por el tema de seguridad. El ex vicepresidente Francisco Santos opinó de manera similar: "Nunca, nunca pensé ver a mi Ejército humillado, como lo veo humillado hoy. Colombia Despierta (...) Jacobo Arenas, Tirofijo, Reyes, Jojoy y Cano deben reír a carcajadas con el mayor triunfo en la historia de las FARC” (León 2012). Así, una parte de la opinión nacional clasificó las acciones indígenas como subversivas, llegando, de forma extrema, a identificarlas con el mismo accionar de la guerrilla. Muestra de ello son las declaraciones del General Alejandro Navas, comandante de las fuerzas armadas, quién sentencio: "los que agredieron a los soldados están infiltrados por las FARC" (Noguera 2012),

Sin embargo, no todas las reacciones de la opinión pública se dieron en ese sentido. Escritores colombianos como Héctor Abad Faciolince prefirieron felicitar a los militares, "que el Ejército se haya portado civilizadamente no es una humillación, es un triunfo" (León 2012), y el periodista Daniel Coronell expresó, refiriéndose a las declaraciones del ex presidente Uribe: "Lo de hoy en el Cauca fue grave, pero no fue una masacre de militares. Hay gente tratando de sacarle provecho político a la situación” (León 2012).

En la ola de los acontecimientos, el concepto de los representantes de la justicia se tornó importante. El Fiscal General de la Nación, Eduardo Montealegre, afirmó, como se lee en la siguiente nota periodística:

Los indígenas del Cauca podrían pagar cárcel si se les llega a comprobar el delito de asonada, por haber atacado a la fuerza pública (...) [el Fiscal General] dijo textualmente que: Lo que quiero significar es que en Colombia no se puede penalizar la protesta social; que la libertad de reunión, las expresiones en la vía pública, son un derecho constitucional (...) pero ya cuando se acude a la violencia, pues lo ha expresado la Corte Constitucional y el Sistema de Interamericano de Derechos Humanos -en esos casos- se puede presentar el delito de asonada. (El País 2012)

En las redes sociales la discusión estaba al orden del día. Entre detractores y defensores, páginas como Facebook y Twitter se llenaron de comentarios que variaban desde la defensa a la autonomía del pueblo Nasa y su decisión de no permitir actores armados en sus territorios, hasta la condena radical de las acciones indígenas. UAIRA ATY?@UairaAty, por ejemplo publicó:"Los indígenas delCAUCA-Colombia, han demostrado su grandeza al decir NO a la guerra, y fuera los actores de la guerra; Legales e 
ilegales”. Otros han defendido la posición indígena basados en la Constitución: "Kiwe Nasa?@KiweNasa: Que las justas exigencias de los hermanos indígenas Nasa del Norte delCauca, gozan de plena disposición legal y constitucional. ONIC”. Algunos más elogiaron la posición de los Indígenas: "Los indígenas del Cauca pusieron en su lugar al Ejército y a las Farc: The Economist”. Las expresiones de simpatía incluyeron muchas del ciudadano de a pie. Por ejemplo, el siguiente mensaje intentó reflexionar sobre las consecuencias de la vecindad con una base militar: "Don Julián?@The_Tripman: yo si entiendo a los indígenas del cauca. Yo tampoco quisiera ser vecino de una base militar”.

En las mismas redes sociales no faltaron los señalamientos de infiltración de las FARC en el movimiento indígena. Durante dos semanas, frases como"Los del Cauca deben respetar a nuestras FF.MM ${ }^{1}$ igual que lo hacen los otros indígenas que representan nuestro pasado” (Duque 2012), se leyeron abundantemente en los diarios y en la web. En Twitter hubo incluso acusaciones como la siguiente: "Verdad para Colombia@miletrina: Los indígenas del Cauca son guiados por líderes que le juegan al plan de masas de las Farc" o "sebastianmorales?@sebasm9417: muchos indígenas del cauca terminan siendo indirectamente cómplices del terrorismo, que los indígenas acepten dialogar con el gobierno”. Colombianos indignados por la reivindicación de los Nasa afirmaron cosas como: “@PalomaValenciaL Los indígenas se están apropiando de toda la tierra del Cauca, y no la trabajan”. Algunos hasta le escribieron al Presidente, advirtiéndole: “Elizabeth Gonzalez@lizzy0714@santos, retire la tropa en el cauca de paso del territorio colombiano y déjele el país y todos nuevos sus amigos (FARC INDIGENAS Y ETC) $)^{2}$.

De esta manera creció la polémica sobre los hechos sucedidos en el Cerro Berlín. Sin embargo, ninguna de las reacciones se aproximó a una explicación sobre la situación, ni mucho menos, vislumbró una salida que no generara controversia. Fueron los mismos indígenas los que, mediante comunicado público el 18 de julio de la Asociación de Cabildos Indígenas, mostraron una ruta para dar fin a la controversia: "Ante el reclamo de que la Guardia Indígena se extralimitó en sus funciones y violó derechos humanos de los soldados, la justicia indígena procederá a la investigación correspondiente; esperamos que el ejército nos formalice la denuncia” (Prensa Indígena 2012). De forma notable, el comunicado abre la posibilidad de un diálogo con el ejército colombiano sin renunciar a la autonomía indígena amparada en la Constitución.

A pesar del impacto mediático tras la toma del Cerro Berlín por los indígenas Nasa, lo que los noticieros de televisión colombianos no explicitaron es que la resistencia indígena a la guerra en esta zona del país no es nueva. De hecho, la toma del Cerro Berlín es un capítulo más de las acciones de todo tipo que los indígenas han emprendido al verse en medio de la guerra, que en sus territorios adquiere una desproporcionada crudeza, como quiera que la guerrilla históricamente ha utilizado el norte del Cauca como posición estratégica en su accionar en el sur-occidente colombiano. 
A su vez, a esta violencia se suman otras violencias aún más antiguas, que también involucran a los indígenas, especialmente en cuanto a la lucha que estos han tenido que emprender para defender sus territorios de los deseos de terratenientes caucanos, desde el mismo inicio de Colombia como proyecto de nación.

No se trata de una reacción inmediata, la resistencia civil indígena ha sido sistemática e histórica, implica una posición política, que las narraciones sobre el Cerro Berlín pasa por alto. "En medio del fragor de las batallas y del orden bélico cerrado, propios de los dispositivos de dominación y de guerra perpetua que se imponen en las poblaciones, han surgido nuevos modos de vida, al calor de la solidaridad y de la capacidad creativa de la gente sencilla que (...) enunciaremos como resistencias sociales. Por su carácter de rupturas con la lógica de la guerra, que les permite desarrollar, su propia capacidad de producción de mundos nuevos, los denominaremos también como modos de resistir noviolentos” (Useche, 2014, 11).

Es importante insistir en que, el Cerro Berlín es apenas un episodio de los muchos que componen la resistencia histórica de los indígenas y de los Nasa en particular. Una resistencia consciente y sistemática, que les ha permitido no solo sobrevivir y reivindicarse como pueblo, sino sobrevivir a la violencia. De estos episodios, debemos aprender sus ejemplos de resistencia civil, desobediencia civil y dignidad, de la lucha por la justicia.

Comprender la resistencia civil implica comprender su trasfondo social y política y su objetivo de transformar pacífica y positivamente situaciones que se consideran injustas, recurriendo a formas alternativas de posturas políticas que rompen con los paradigmas clásicos de la concepción de poder y de política, situándose en lo micro y macro político.

"La resistencia civil es un método de lucha política basada en la idea básica de que los gobiernos dependen en último término de la colaboración, o por lo menos de la obediencia de la mayoría de la población, y de la lealtad de los militares, la policía y de los servicios de seguridad civil (...) sus métodos abarcan desde la protesta y la persuasión hasta la no cooperación social, económica y política, y por último hasta la intervención noviolenta” (Randle 1998, 25).

Ahora bien, es preciso recordar el largo debate teórico del derecho de resistencia en la construcción democrática de los Estados o las organizaciones políticas, colocando de manifiesto que ningún régimen político garantiza ante la dinámica compleja de la humanidad los principios fundamentales, ni una ética infalible, ante lo cual, el derecho de resistencia cuestionará las formas y hará perfectible la organización. "La aceptación, reconocimiento y ejercicio de esos principios éticos absolutos universales, entre los cuales se encuentra el derecho de resistencia, depende, de un modo diríamos connatural, la existencia misma de la democracia. Una de las posibles manifestaciones de esta ética universal tiene su formulación teórica concreta en la teoría de los derechos humanos” (Carvajal, 1992, p.67). 
Estas posturas alternativas al poder y especialmente a la guerra, revalúa el concepto de revolución, y sugiere prácticas que conservan la humanidad misma, sin recurrir a la violencia, pero con una vehemente posición frente a las injusticias y desacuerdos. Deconstruyen y construyen colectivamente. Forman nuevos paradigmas e invitan a reflexionar. (Ballesteros, 2014). La resistencia civil tiene una cualidad ético -política, es una forma de lucha noviolenta: "De esta manera, las tácticas y los métodos de resistencia activa, dinámica, creativa y participativa; así como las formas de no cooperación, desobediencia civil, etc., quedan salvaguardadas no sólo por su renuncia al uso de la violencia sino también por su fundamentación ética y su coherencia axiológica (López Martínez 2001, 208).

Los medios de comunicación tampoco entendieron a cabalidad las palabras de Feliciano Valencia. La consigna del pueblo Nasa frente al conflicto armado es decidida y fundamentada en lo que ellos mismos consideran como bueno, deseable y justo para su propia comunidad. Y es que, como ellos mismos lo han dicho, la posición en la que se encuentran en medio de las balas de uno y otro lado amenaza seriamente su continuidad como pueblo y como cultura.

No nos vamos a quedar de brazos cruzados mirando cómo nos matan y destruyen nuestros territorios, comunidades, planes de vida y nuestro proceso organizativo. Por esto, enraizados en la palabra, la razón, el respeto y la dignidad, iniciamos caminar en grupos hasta donde están atrincherados los grupos y ejércitos armados, para decirles frente a frente, que en el marco de la autonomía que nos asiste, les exigimos que se vayan, que no los queremos, que nos cansamos de la muerte, que están equivocados y que nos dejen vivir en paz. (verdadabierta.com 2012)

Posición decidida que no riñe ni con el régimen político ni con las leyes. Volviendo a las palabras del líder del CRIC, "respetamos al gobierno y a la constitución”. En esta declaración, Valencia reconoce que la decisión de expulsar a los soldados tanto del Cerro Berlín como de sus territorios obedece no a una oposición al Estado como tal, sino se trata de la desobediencia a una política particular y a la manera en cómo el Estado colombiano enfrenta el conflicto armado.

Es preciso retomar en este momento el concepto de desobediencia civil: "negarse a cumplir con una disposición legislativa, normativa o de política pública ${ }^{3}$, con el objetivo de transformarla, porque se considera que genera algún tipo de injusticia y se encuentra evidentemente en contra de la conciencia moral del desobediente” (Ballesteros, 2014, p.286); y se debe agregar que la desobediencia civil es un instrumento de la lucha noviolenta, para corregir alguna cuestión del sistema político que genera injusticia. Convivir en medio del fragor de la guerra es en sí mismo es una situación que genera injusticia, rechazar con vehemencia la violencia armada venga de donde venga es una postura ética cuyo objetivo es la vida misma. 
El fenómeno de la desobediencia civil es seguramente una expresión del malestar de la democracia, y surge claramente en el momento en que las reglas del juego democrático se desnaturalizan sin que por ello se vea alterada completamente la confianza en su funcionamiento (Ugartemendia 1999, 77).

Los indígenas Nasa son reiterativos en afirmar que no están en contra del gobierno ni del Estado. Disienten de las formas como se ha querido enfrentar los problemas de seguridad. La definición que se ha ofrecido de desobediencia civil nos conlleva a anotar que implica que los desobedientes, en este caso los indígenas, cuestionan asuntos de interés público e invitan a la deliberación, a la confrontación política, específicamente en el campo ético. Nos retan a pensar en formas alternativas de hacerle frente a la violencia sin violencia. De allí la importancia de pensar y actuar en términos de noviolencia.

La desobediencia civil se caracteriza por ser consciente, pacífica, pública, responsable y democrática. Es decir, producto de nuestra capacidad de discernimiento y por lo tanto de decisión autónoma de obedecer o desobedecer. Es un acto que no debe producir más daño, ni violentar a otros, cuyas razones de justificación se someten a la deliberación pública, reflejo de la responsabilidad que se asume en ejercicio de la ciudadanía. La desobediencia civil debe ser un instrumento de las democracias actuales. Sus principios son la libertad, los derechos fundamentales y la noviolencia como agente protector de los dos primeros anteriores. (Ballesteros, 2014)

Los hechos del Cerro Berlín deben a su vez contemplarse, al menos, en el marco de las diferentes acciones emprendidas en todo el mes de julio por los indígenas Nasa. Entre estos pueden contarse, por ejemplo, la destrucción de tres trincheras de la Policía Nacional en Toribio, el rodeo al puesto militar en monte Redondo (Miranda-Cauca) el 10 de julio de 2012, y la marcha al caserío de Huasanó exigiendo el retiro del Ejército, en el cual hubo tiroteos con resultado de un campesino muerto y tres heridos (Sierra 2012). De igual forma los indígenas han emprendido temerarias acciones frente a la guerrilla. Así, quitaron dos retenes de las FARC en la carretera hacia Santander de Quilichao, detuvieron a cuatro guerrilleros en las afueras de Toribio, procediendo luego a enjuiciarlos públicamente.

Estas acciones como se ha dicho se suman a una multiplicidad de acciones históricas del pueblo Nasa en el marco de su proyecto de resistencia, cuyo origen surge por iniciativa del sacerdote indígena jesuita Álvaro Ulcue Chocue, en 1980 y cubre los resguardos indígenas de Toribío, San Francisco y Tacueyó. Los grupos del proyecto Nasa declaran que "la resistencia comunitaria indígena, es entendida como un proceso, como un reto de 84 pueblos indígenas de Colombia y los demás pueblos indígenas de América Latina, no sólo frente a un mundo globalizado, sino armar una propuesta alternativa, Latinoamericana, una resistencia que tiene que ser desde distintos ángulos, una resistencia también a los grupos armados” (Hernández, 2004, p.126). 
Los indígenas del norte del Cauca se han levantado en resistencia contra el colonialismo, el servilismo, el terraje, la defensa por la tierra que es la misma madre, por la dignidad, por la autonomía y la libertad. Comprendieron hace mucho tiempo que la guerra no es funcional, ni logrará la conservación de la vida. Por eso desde hace décadas se han declarado en resistencia civil.

"La cosmovisión de este pueblo resistente concibe al mundo y a la vida como una dinámica perpetua, una metamorfosis ejemplificada en el cambio de formas de las mariposas o en el cambio de piel de las serpientes (des- escamar); este es para ellos, el mayor regalo de los ancianos sabios, que crearon el mundo. La resistencia es entonces un mandato de vida que fluye, es tan natural y decisiva como el tremor de la tierra, ante los embates de las fuerzas que intentan cambiar su curso e impedir que se afiance en su naturaleza de ser” (Useche, 2014, 507).

Esta resistencia tiene su anclaje no solo en el descredito de la violencia, sino en la fuerza creadora alternativa que ofrece las luchas noviolentas, en armonía con la conservación y la paz, en línea con la cosmogonía propia; de esta manera se entrelazan el mundo espiritual nasa y los principios éticos del hinduismo, para coincidir en la noviolencia, como lucha válida en la reivindicación de la justicia. (...) La noviolencia, en su versión política, es un gobierno sobre la base de que ninguno usará la fuerza violenta sino la de las convicciones y las razones, porque no basta con ser simplemente demócrata, liberal o socialista, sino un desobediente e insatisfecho ante las injusticias del mundo (Capitini citado por López Martínez 2012, 15).

Esto implica por parte del pueblo Nasa, disciplina, constancia, innovación, creatividad, fuerza, coherencia y defensa. Por siglos han tenido que hacerle frente a la violencia. Han elegido una forma de lucha diferente a la lógica tradicional, rompen los esquemas de la violencia tradicional. Se han cansado de la guerra. Pero no dejaran de luchar por su dignidad: "La noviolencia requiere de personas (...) emprendedoras, inquietas, que se hagan interrogantes para crecer mental y espiritualmente. Personas que obedezcan la voz de su conciencia, gentes que ejerzan su capacidad de poder para cambiar las injusticias del mundo, que sean desobedientes frente a la abyección, objetores de conciencia respecto del mal... (López Martínez 2001, 210).

Gandhi desarrolló el concepto de la noviolencia como aquella acción política activa cuyo principio básico moral es ahimsa (no hacer daño), que busca la verdad con la fuerza de la persistencia y la perseverancia (satyagraha). Nunca está de más insistir en que la noviolencia no es sinónimo de debilidad, pasividad, utopía imposible, impotencia, indiferencia, ni de aceptación a las determinaciones del poder (López Martínez, 2009, 8-14). De ahí que podamos ver cómo la desobediencia y la resistencia participa, asimismo, de muchas de esas características que atribuimos a la noviolencia y que, en consecuencia, podríamos usar para ambos conceptos. 
Para los Nasa entonces, "resistir es cuidar, clamar por la defensa de la gran casa (la tierra) y afianzar el plan de vida y dignidad de los pueblos indígenas" (Useche, 2014, 507). Las acciones que emprenden se encuentran en el marco de los principios de vida, territorio, autonomía y dignidad, con lo cual las resistencias y desobediencias civiles indígenas son formas que guardan coherencia con sus principios rectores.

Lo que aquí se configura es una lucha histórica, que hace frente a la violencia sin violencia, con métodos alternativos y creativos, con métodos de lucha noviolenta como la resistencia y la desobediencia civil.

Por otro lado, con respecto a los hechos del Cerro Berlín, la reacción de la academia colombiana fue prácticamente nula. Salvo algunos artículos y editoriales de prensa, especialmente en medios alternativos de difusión, no hubo una discusión sobre lo que significan las acciones indígenas de cara al largo conflicto armado colombiano. El debate giró en torno a la preocupación por armonizar el derecho de autonomía de los territorios indígenas -reconocido por la Constitución de 1991-y el deber constitucional del Estado de preservar el orden público en todo el territorio nacional. La cuestión se presentó en forma de dilema, como si la presencia del Estado y la defensa del orden público sólo pudiesen hacerse a través de las armas, reduciendo el Estado a las Fuerzas Armadas. De esta manera, muy en consonancia con la tradición legalista colombiana, la discusión del problema fue prácticamente monopolizada por los más expertos abogados constitucionalistas, quienes tendrían que evaluar si prevalece el derecho de la autonomía de los territorios indígenas, el respeto y el reconocimiento de una nación pluriétnica, o el deber del Estado de preservar la seguridad para garantizar los derechos y libertades, bajo el único instrumento que conocen, el monopolio de la fuerza.

En entrevista con Lasillavacia.com - un medio de comunicación interactivo, ampliamente consultado en Colombia - el ex magistrado de la Corte Constitucional, Alfredo Beltrán, afirmó que "la autonomía (indígena) que tienen sobre esos territorios está limitada a la observancia de la Constitución y de la ley” (Maya 2012). Con esta afirmación coincidió el ex director del Programa Presidencial de Derechos Humanos durante el gobierno de Álvaro Uribe, Carlos Franco: "En todas partes se le atribuye al Presidente el manejo del orden público. Por eso la autonomía de las comunidades no es absoluta y está limitada en este tema” (Maya 2012). Mientras, el doctor en Ciencia Política y profesor de la Universidad de los Andes, Iván Orozco, abogó por la necesidad de una mediación: "Me parece razonable que en un modelo presidencialista como el colombiano los actos últimos de afirmación de soberanía sobre el territorio correspondan, en buena medida, a actos presidenciales, pero insisto en que para el caso de las comunidades indígenas es importante la figura del mediador” (Maya 2012). Afirmación a la que se sumó el ex magistrado de la Corte Constitucional José Gregorio Hernández: “(...) es necesario que se llegue a un acuerdo entre ambas partes, más aún si en un caso como éste se trata de la protección y defensa de las comunidades y debería interesarles llegar a un acuerdo. 
El Gobierno debe garantizar su seguridad pero para ello debe antes consultarlos” (Maya 2012).

En este contexto, es pertinente recordar que estas formas de lucha de una u otra forma cuestionan el régimen político y social, por lo tanto, termina siendo prueba de constitucionalidad. Arendt resuelve esta discusión también con una propuesta audaz, incluir la figura de la desobediencia civil como norma constitucional (Arendt 1999, 61), lo cual giraría la discusión sobre lo realmente trascendente: cambiar las formas en las que el Estado pretende resolver el tema de orden público. Al fin de cuentas, lo que los indígenas controvierten en este punto es su vulnerabilidad por encontrarse en medio del fuego cruzado.

Estos acontecimientos se convierten en una oportunidad única de explicar la resistencia civil y de ofrecer un concepto de desobediencia civil, que permitiera romper con el dilema en la discusión pública y pudiera comprender que la postura Nasa frente a la guerra es compatible con la democracia, los derechos de las comunidades indígenas y el deber del Estado. Precisamente, ante la incesante presión mediática y el abordaje de los acontecimientos como una disyuntiva entre el respeto por la autonomía indígena y la presencia de las fuerzas armadas, el Presidente de la República declaró:

Éste es un Gobierno que le abre las puertas al diálogo. Queremos concertar las soluciones. Pero hay asuntos donde quiero reiterar que nosotros no podemos ceder un solo milímetro; nosotros no podemos ceder un centímetro de nuestro territorio. La presencia de la Fuerza Pública no es negociable, en ninguna parte del territorio, y que cualquier diálogo no puede depender que ese tema esté sobre la mesa, porque ese tema no es negociable (Santos 2012).

Para el analista, la pregunta que surge ante la declaración del presidente es: ¿cómo dialogan sobre una situación que de entrada califican de innegociable? Las partes declaran que se respetan y se reconocen, pero dicho respeto y reconocimiento no se traduce en la posibilidad de dialogar sobre las disidencias. De esta manera, no sólo se estableció una mesa de diálogo en el que el asunto principal que los convoca no se abordaría, sino que además se creó de manera paralela un delegado presidencial para coordinar con los ministerios la ejecución de proyectos sociales y un general a cargo de un recién creado Comando Conjunto del Suroccidente para que continuara con la estrategia militar que se venía desarrollando. En conclusión, no sólo no se atendía el asunto de controversia sino que se insistía en la continuidad de lo que se venía desarrollando, precisamente aquello a lo que estaban desobedeciendo los indígenas. El punto es que, precisamente, los hechos del Cerro Berlín, se convierten en un acto de desobediencia civil de los indígenas, que hace evidente una situación que genera injusticia y que, guardando fidelidad con la democracia constitucional, busca generar un debate público que permita ajustar o reformar la situación que denuncia. De esa manera, las acciones indígenas podrían contemplarse como un ele- 
mento de transformación política positiva, si se entiende que la compleja dinámica de las democracias exige permanentes adaptaciones sin perjuicio de los derechos fundamentales ni de las normas constitucionales. Además de coherencia entre fines y medios lo cual ofrece las luchas noviolentas.

La incomprensión sobre figuras como la protesta social, la resistencia y la desobediencia civil no permitió abordar una discusión serena, rigurosa, participativa y juiciosa sobre la postura de los indígenas Nasa, como tampoco permitió explorar alternativas de complementariedad entre su autonomía y la garantía de seguridad en el territorio, la incorporación de la guardia civil indígena en una estrategia conjunta de rechazo a la guerrilla de las FARC, la visibilización de los programas sociales en el departamento del Cauca y la estrategia en materia de garantía de derechos y libertades. Aunque se reiteraba el respeto entre unos y otros, el Presidente anunció que en la incautación del computador de un cabecilla de las FARC, alias Pacho Chino, se encontró el siguiente mensaje: "Repartir propaganda en los municipios del norte del Cauca para que la población le exija a la Fuerza Pública el retiro de las áreas pobladas", para luego agregar: "Yo creo que esto habla por sí solo, sin acusar ni mucho menos a los indígenas de estar confabulados con las Farc” (Santos 2012).

Por su parte, la Asociación de Cabildos Indígenas del CxhabWalaKiwe -ACIN_-, lamentó las declaraciones que se hacen sobre infiltraciones de las FARC en el movimiento indígena, denunciando que después de la decisión presidencial de retomar el Cerro Berlín, hubo heridos y muertos que los medios de comunicación no registraron:

No hubo prensa que mostrara las agresiones de que fuimos víctimas. Hasta el momento hay 26 heridos indígenas, cuatro con papa-bomba y otro con disparo de arma de fuego, así como 1 detenido y cerca de 10 con paradero desconocido (...) (Prensa Indígena 2012)

Si se pudiera comprender la protesta, la resistencia o la desobediencia civil, como un elemento que puede abordar debates neurálgicos, colocando en el debate público cuestiones éticas y posiciones políticas en las que los ciudadanos participan activamente y deciden sobre las formas como deberían resolverse las situaciones complejas, haciéndose responsables de sus exigencias y decisiones, entonces podría identificarse en la posición de los indígenas una oportunidad para hacer del Estado una representación de la decisión política de los ciudadanos.

En esencia las practicas noviolentas, en este caso las resistencias y desobediencias, siguen la lógica de la lucha contra la injusticia, no prestan colaboración a lo que consideran injusto, hacen pública su posición e invitan a debatir sobre estas prácticas que rechazan, sin que implique un cuestionamiento a todo el entramado del Estado. Es indudable que dichas prácticas se encuentran en una sinfín de complejidades contextuales, pero la dificultad más evidente son las contradicciones argumentativas para abordar el incidente: dialogamos, pero no sobre los acontecimientos, respeta- 
mos la autonomía, pero no dejaremos que la ejerzan, vamos a concertar sobre los principios que las partes no han cuestionado. A lo que se suma la falta de conocimiento de su lucha milenaria y de estas formas como mecanismos de participación que fortalecen una democracia inacabada por la dinámica misma de la humanidad.

Ahora bien, se puede identificar con cierta claridad que el mayor temor del Estado es que la guardia indígena no pueda repeler una toma de las FARC, y termine incrementándose el ya caótico orden público que se presenta en la zona. Por su parte, algunos indígenas Nasa manifiestan temor ante la posibilidad que se incremente la criminalidad o la perpetración de las FARC ante la ausencia de fuerza pública.

(...) El portavoz de ACIN reconoció que sí existe división entre algunos indígenas que no están de acuerdo con que la fuerza pública abandone la zona porque varias personas tienen miedo de que los bancos también abandonen los municipios y con ellos las iniciativas de diferentes proyectos productivos (Semana.com 2012).

Sin embargo, la mayoría de ellos considera que su acción de retirar a todos los actores armados redundará en la protección de sus vidas y en evitar estar en medio de los enfrentamientos armados, lo cual ha cobrado cientos de vida en las casi cinco décadas que ha durado el conflicto armado en la zona.

Al temor del Estado, se le suma asimilar una figura como la desobediencia o la resistencia civil a subversión, insurgencia o asonada. El Fiscal General de la Nación, Eduardo Montealegre, dijo que“los indígenas del Cauca podrían pagar cárcel si se les llega comprobar el delito de asonada, por haber atacado a la Fuerza Pública” (Elpais.com 2012). Poco tiempo después de la toma, el Presidente de la República dio órdenes a la fuerza pública de retomar el Cerro donde los indígenas habían corrido a los militares y al ministro del interior de establecer una mesa de diálogo:

Anoche con el señor Ministro (de Defensa, Juan Carlos Pinzón) dimos unas instrucciones muy precisas; las instrucciones eran que hay que retomarse la base militar del cerro de La Estrella, donde sucedieron los hechos que el país conoció el día de ayer. Al mismo tiempo dimos la instrucción y autoricé al Ministro del Interior a que tuviera toda la disposición para el diálogo como lo hemos venido haciendo desde un principio (...) (Santos 2012)

Dos instrucciones evidentemente contradictorias, continuando con la tónica que aquí se ha intentado delinear. Por ello, no debe sorprender que mientras parte del Gobierno habla de respeto y diálogo, el Ministerio de Defensa intentó argumentar que las acciones indígenas se trataron de una acción de las FARC:

Lo que quieren es que la Fuerza Pública salga para ellos quedar 
soberanos ahí. Todo eso está sucediendo porque las Farc quieren 'caguanizar’4 el Cauca con el argumento de la autonomía indígena, sostuvo Navas, quien dice que no tiene dudas de que en la revuelta de ayer estuvo infiltrada por las Farc: Ahí hay milicianos, están ahí confundidos con esa población civil que la utilizan como escudos. (Eltiempo.com 2012)

Por su parte las FARC anunciaron que se retirarían si también lo hacía el ejército y la policía, en una clara provocación a un Estado compungido por la situación: “(...) el Gobierno notificó que no retirará las fuerzas de seguridad de ningún lugar y ordenó la retoma de sus posiciones, mientras que los insurgentes condicionaron su salida a la de sus contendientes”. (EFE 2012).

Entre asociar la postura indígena frente al conflicto armado con la asonada y la insurgencia, y el temor de que las FARC logrará sacar algún provecho de la situación, se anuló cualquier posibilidad de comprender los hechos mediante figuras como la desobediencia o la resistencia civil, que podrían explicar mucho mejor los acontecimientos aquí referidos. Desde una postura dispuesta al diálogo, lo allí sucedido significa de hecho una oportunidad para, a partir del debate, afrontar de otra manera el conflicto armado en territorios indígenas, en primera instancia, y en el país en general. El punto crucial y que no es en ningún caso así identificado, es que la desobediencia civil, por ejemplo, está acorde no sólo con los principios de libertades y derechos sino con el desarrollo democrático de lo que conocemos como Estado.

En primer lugar, la desobediencia civil permite corregir cuestiones que generan algún tipo de injusticia, sin tener que derogar el sistema político en cuestión o sin la pretensión de subvertir el orden establecido. El desobediente civil hace evidentes varios temas éticos y políticos sustanciales en la construcción de la democracia, tales como: la conservación de los principios, la participación, la autonomía y la moralidad. Con sus actos, los indígenas Nasa fundamentalmente están expresando que en la forma de abordar el conflicto armado en Colombia se vulneran sus derechos. Su actitud es participativa y autónoma, en el marco de la constitución y las leyes que los amparan, sugieren debatir lo que les afecta en todos los aspectos de su cotidianidad. La imagen no puede ser más evidente: si es preciso, la comunidad indígena sacará a rastras a los actores del conflicto que hacen presencia en su territorio. Cuando Feliciano Valencia dice que los indígenas están "cansados de la guerra”, no hace sino dar palabras a lo que luego la guardia llevaría a los hechos.

Es indispensable entender no sólo los hechos del Cerro Berlín, sino especialmente el marco de acciones y declaraciones de los líderes y comuneros indígenas en el que se insertan, como actos de desobediencia. Como ya lo hemos dicho, los indígenas no están oponiéndose ni al Estado ni al Gobierno, pero sí desobedecen activamente una política específica, aquella que determina la forma en que se enfrenta el conflicto en sus territorios. 
Insistir que sus manifestaciones son contra unas formas de acción del Estado, no contra todo el estamento o la organización. Es clarísimo, están contra cualquier forma de violencia, están contra la guerra y sus consecuencias, y rechazan enfrentar la guerra con más violencia.

Por otra parte, el desobediente civil evidencia que se está fallando en algún principio, particularmente en materia de justicia. En un ejercicio de autonomía y moralidad, actúa desobedeciendo una ley o política que debe ser una representación de su propia moralidad y de la ética colectiva. De esta manera, hace evidente la imperiosa necesidad de discutir sobre el asunto y de realizar los ajustes correspondientes. Lo cual es una forma no sólo de participación sino también de ciudadanía activa.

Se trata de un hecho que ilustra la desobediencia civil. El célebre autor clásico Henry David Thoreau, quien conceptualizó el término en su ensayo Del deber de la Desobediencia Civil en 1848 señala sencillamente que: ante una ley injusta, el deber ciudadano es desobedecerla e instar al gobierno a su reforma (Thoreau (1848) 2008). Llamando a la coherencia entre la vida práctica con los principios éticos y las ideas liberales. El ensayo de Thoreau nace precisamente de su negativa a pagar impuestos dirigidos a financiar la guerra contra México. Para Thoreau era incoherente formar una república con base en el sometimiento de otra nación.

Estudiar y conocer la desobediencia civil permite adicionalmente recordar que la construcción del Estado tiene un objetivo: el de preservar los derechos y las libertades de los ciudadanos. El régimen político sólo es posible en la medida que los ciudadanos consientan la forma de gobierno y que las leyes sean una representación de los acuerdos morales y éticos.

Thoreau es enfático en reconocer el derecho de resistencia, señala como injusto y contradictorio considerar la resistencia como un derecho para la recién constituida república de los Estados Unidos, pero negar este derecho a los pueblos que son conquistados y sometidos.

(...) cuando una sexta parte de la población de un país que se ha comprometido a ser refugio de la libertad, está esclavizada, y toda una nación es agredida y conquistada injustamente por un ejército extranjero y sometida a la ley marcial, creo que ha llegado el momento de que los hombres honrados se rebelen y se subleven. Y este deber es tanto más urgente, por cuanto que el país así ultrajado no es el nuestro, sino que el nuestro es el invasor (Thoreau [1848] 2008, 34).

El discurso de Thoreau nos sirve para reflexionar sobre los derechos que proclamamos como nación y los derechos que reconocemos para los pueblos indígenas. Este episodio del Cerro Berlín nos sirve como excusa para señalar que la autonomía de los pueblos indígenas sigue siendo restringida y que algunas de sus posturas son cuestionadas, como la que han tomado frente a la guerra. 
Si el Estado colombiano se diera la oportunidad de comprender en este sentido la serie de acontecimientos que alcanzaron su cenit de confrontación en el Cerro Berlín, tal vez se podrían encontrar nuevas vías para construir alternativas que respondan a una realidad compleja y diversa. La dinámica de los acontecimientos podría así utilizarse para consolidar la propuesta democrática que, al menos en teoría, supone el Estado colombiano.

En ese sentido, es preciso que el lector comprenda la figura de la desobediencia civil como un elemento eminentemente político, que expresa la relación moral del ciudadano con la ley, con lo público, con la política, con el poder y con el Estado.

En ese abordaje es necesario recordar que la obligación política de la obediencia a las leyes tiene una fundamentación moral y ética, una coherencia lógica para la garantía de los derechos y el desarrollo de las libertades, y esos mismos argumentos que se tienen para la obediencia son los mismos que deben motivar la desobediencia en los casos en que la ley permita alguna injusticia o se presente alguna incoherencia con los principios pactados en las constituciones políticas.

Desobedecer es una forma de relacionarse con el poder, que además abre a lo público cuestiones pertinentes como la coherencia entre la moral y la obediencia. La desobediencia indígena reclama cambios necesarios que permitan coherencia entre lo que se busca: convivencia, respeto, libertad y los medios para hacerlo: noviolencia. Para el desobediente, es importante establecer una detallada relación entre medios y fines. Así lo hace el pueblo Nasa, cuestiona la violencia con la que se enfrenta la violencia misma. El desobediente civil no puede seguir nunca la máxima maquiavélica de "el fin justifica los medios", pues para el desobediente civil los medios son fines en sí mismos (la expresión de la inconformidad y a través de ella el empoderamiento por la desobediencia), y el fin es a su vez un medio para alcanzar fines aún mayores, enmarcados en la confrontación con la injusticia.

Finalmente, lo que debe comprenderse es que los hechos del Cerro Berlín, deben interpretarse desde las luchas contra la injusticia, que recoge los estudios de la noviolencia (Cappetini 1992, Gandhi (1948) 2004, López 2009, 2011, Muller 2004, 201, Useche 2014,) y sus formas de expresión como la protesta, la insumisión, la objeción de conciencia, la resistencia, la desobediencia, etc. (Ballesteros 2014,López 2009, 2011, Martínez 2011, Useche 2014) 
Polis, Revista Latinoamericana, Volumen 15, $N^{\circ}$ 43, 2016

\section{Notas}

${ }^{1}$ FFMM: siglas para referirse a Fuerzas Militares.

${ }^{2}$ Mayúsculas en el original.

${ }^{3}$ Una política pública es una disposición estatal o gubernamental que responde a una demanda de la sociedad y determina una serie de disposiciones normativas, administrativas y de servicios. El profesor Alejo Vargas (1999) explica que es una iniciativa, decisión o acción del Estado frente a una situación problemática. Por tratarse de disposiciones que responden generalmente a la racionalidad técnica, tiene el riesgo de desestimar la deliberación pública y la participación, ocasionando algunas veces injusticias.

${ }^{4}$ Durante el Gobierno de Andrés Pastrana (1998 - 2002), se desmilitarizo la zona del Caguán - Caquetá, Colombia) por parte de las Fuerzas Armadas de Colombia, con el objetivo de desarrollar una mesa de diálogo con las FARC. Al tiempo que en el resto del territorio Colombiano continuaban las hostilidades del conflicto armado colombiano. El "despeje" como se le conoció a este hecho, le sirvió a la guerrilla de las FARC para cometer actos como tráfico de drogas, retención de secuestrados, reclutamiento y planeación del desarrollo de sus estrategias militares, políticas y diplomáticas. Mantuvieron secuestrados en la región a más de 450 militares y policías secuestrados. La sensación que este hecho dejo en la opinión pública, es que la posición flexible del gobierno sirvió para que las FARC recrudecieran la guerra y cometieran cientos de secuestros. Los diálogos de paz finalizaron el 20 de febrero de 2002 y el conflicto armado colombiano recrudeció sus acciones militares. "Caguanizar” significa entonces entregar una zona desmilitarizada a las FARC, para que ésta lo utilice en pro del recrudecimiento de su acción armada. 


\section{Bibliografía}

Arendt, Hannah (1999), Crisis de la República. Taurus, Madrid.

Arias, Diego (2012), “Conflicto en el Cauca: ¿Santos aprendió la lección?”, Semana.com, 26 de julio.

Ballesteros, Gilma Liliana (2014), Desobediencia civil: un análisis político. Ed. Universidad de Granada, Granada.

Capitini, Aldo (1992), Scrittisullanonviolenza. Protagon, Perugia.

Duque Naranjo, Lisandro (2012), “Colombia resultó blanca”, Elespectador.com, 22 de julio.

EFE (2012), “Indígenas del Cauca y Gobierno retomarán diálogo este miércoles”. Eltiempo.com, 7 de agosto. http://www.eltiempo.com/politica/ indigenas-del-cauca-y-gobierno-retomaran-dialogo-este-miercoles-12106641-4

ElPais.com (2012), “Indígenas del Cauca podrían ir a la cárcel si se comprueba delito de asonada: Fiscalía”, 18 de julio. http://www.elpais.com.co/ elpais/judicial/noticias/indigenas-del-cauca-podrian-ir-carcel-si-compruebadelito-asonada-fiscalia

ElPlaneta.com (2012), “Desalojo en el cerro Berlín genera reacción nacional”, 18 de julio.

Eltiempo.com (2012), “Las Farc quieren Caguanizar el Cauca”, 17 de julio.

Gandhi [1948] (2004), Escritos esenciales, Sal Terrae, Bilbao.

Hernández Delgado, Esperanza (2004), Resistencia Civil Artesana de Paz, Ed. Pontificia Universidad Javeriana, Bogotá.

León, Juanita (2012), “¿Valdrá esta imagen la reelección de Santos?”. lasillavacia.com, 18 de agosto.

López Martínez, Mario (2009), Política sin violencia. La noviolencia como humanización de la política, Corporación Universitaria Minuto de Dios, Bogotá.

Ídem (2013), “Política sin matar: los métodos de la acción no-violenta”. Revista Vectores de Investigación. 7: 33-84.

Martínez, Carlos E. (2011), Los nuevos movimientos sociales y cambio de paradigmas en el último siglo a través de la lógica de la Noviolencia, Universidad Granada, Granada, España. 
Maya, Martha (2012), “Cuáles son los límites de la autonomía indígena según los expertos”, lasillavacia.com, 19 de julio. .

Muller, Jean-Marie (2004), El coraje de la noviolencia: nuevo itinerario filosófico, Sal Terrae, Maliaño.

Ídem (2011), L’impératif de la désobéissance. Fondementsphilosophiques et stratégiques de la désobéissancecivile. Le PrésaintGervais: Le passagerclandestin.

Murcia, Luis Ángel (2012), “Cauca: Un día de furia y vergüenza en Berlín, el cerro de Toribío”, Semana.com, 18 de julio.http://www.semana.com/ nacion/cauca-dia-furia-verguenza-berlin-cerro-toribio/180985-3.aspx

Noguera, Luisa (2005), Mahatma Gandhi, la fuerza del alma, Panamericana, Bogotá.

Prensa Indígena (blog) (2012), “Colombia: Comunicado sobre los hechos del Cerro el Berlín”.

Randle Michael (1998), Resistencia Civil, Paidós, Barcelona.

Santos, Juan Manuel (2012) “Comunicado Oficial de 18 de Julio”, Presidencia.com.

Thoreau, Henry David [1848] (2008a), Desobediencia Civil y otros escritos. Juan José Coy (comp.), Tecnos, Madrid.

Ugartemendia, Juan Ignacio (1999), La desobediencia civil en el Estado constitucional democrático, Marcial Pons, Madrid.

Useche, Óscar (2014), El acontecimiento de las resistencias sociales: Micro política de las revoluciones noviolentas como apertura de nuevos territorios existenciales. Ed. Universidad de Granada, http://digibug.ugr.es/ bitstream/10481/34191/1/24049955.pdf 